\title{
O ELETROLIFTING COMO UMA ALTERNATIVA NO TRATAMENTO DE ESTRIAS
}

\section{ARTIGO DE REVISÃO}

BESSA, Vicente Alberto Lima ${ }^{1}$

BESSA, Maria Fátima de Sousa²

BESSA, Vicente Alberto Lima. BESSA, Maria Fátima de Sousa. O eletrolifting como uma alternativa no tratamento de estrias. Revista Científica Multidisciplinar Núcleo do Conhecimento. Ano 04, Ed. 07, Vol. 11, pp. 67-78. Julho de 2019. ISSN: 2448-0959

\section{RESUMO}

As estrias são atrofias da pele adquiridas que surgem quando as fibras elásticas e colágenas se rompem e formam "cicatrizes". Elas podem causar um impacto no estado emocional, além do dano estético. Há vários tipos de tratamentos que podem ser empregados pelo esteticista para tratar as estrias, dentre eles: o eletrolifting. Portanto, foi realizado um estudo de revisão bibliográfica com o objetivo de investigar os benefícios morfofuncionais que podem ser obtidos no tratamento de estrias pela aplicação do eletrolifting. E pode-se inferir que o eletrolifting melhora a vascularização, aumenta o número de fibroblastos jovens ampliando a síntese de proteínas, além de

1 Mestre em Ciências da Motricidade Humana; Especialização em Fisioterapia Dermato-funcional; Especialização em Treinamento Desportivo e Personal Trainner; Especialização em Ginástica Médica; Especialização em Língua Portuguesa Especialização em Tópicos Avançados em Fisioterapia; Especialização em Docência Inovadora do Ensino Superior; Graduado em Fisioterapia; Tecnólogo em Estética e Cosmética; Bacharel e Licenciado em Educação Física; Licenciado em Letras; Licenciado em Pedagogia.

${ }^{2}$ Mestre em Ciências da Motricidade Humana; Especialização em Ginástica Médica; Graduada em Fisioterapia; Bacharel e Licenciada em Educação Física. 
facilitar a migração de queratinócitos e macrófagos, e tem efeito antioxidante e antidislipidêmico. Esses fenômenos resultam na reparação tissular e minimiza o aspecto da estria.

Palavras-chave: estrias, eletrolifting, microgalvanopuntura.

\section{INTRODUÇÃO}

A Organização Mundial de Saúde em 1948 estabeleceu um conceito de saúde que vigora até hoje. Ela considera que a saúde envolve o bem-estar físico, mental e social da pessoa (BRASIL, 1997). Apesar das estrias não gerarem uma ameaça à saúde, eles podem ser psicologicamente angustiantes. (BERGFELD, 1999). Sendo assim, a presença de estrias pode representar uma ameaça à integridade emocional da pessoa e, portanto, comprometer a autoestima.

É mister ressaltar que há vários procedimentos que podem ser utilizados no tratamento das estrias, dentre eles microdermoabrasão, laser, carboxiterapia, radiofrequência, vacuoterapia, peelings, indução percutânea de colágeno com o microagulhamento e o eletrolifting (Moreira et al, 2013, MCCRUDDEN et al, 2015).

Hoje em dia, muitos buscam tratar as estrias e um dos procedimentos utilizados é o eletrolifting, que promove um processo inflamatório que irá estimular a regeneração dos tecidos e desta forma suavizará as estrias e as tornará menos perceptivas. (SILVA, ROSA, SILVA, 2017).

Sabendo-se que o eletrolifting poderá ser aplicado para tratar pessoas com estrias, surgiu a seguinte situação problema: quais serão os benefícios morfofuncionais que este procedimento pode promover.

\section{OBJETIVO GERAL}

- Investigar os benefícios morfofuncionais que podem ser obtidos no tratamento de estrias pela aplicação do eletrolifting. 


\section{OBJETIVOS ESPECÍFICOS}

- Determinar as causas do aparecimento das estrias e seus tipos.

- Descrever os benefícios morfofuncionais promovidos pelo eletrolifting ao se tratar estrias.

- Identificar as técnicas de eletrolifting que podem ser aplicadas no tratamento de estrias.

\section{JUSTIFICATIVA}

As estrias são cicatrizes que se formam devido às lesões tissulares que produzem aspecto inestético. Essa condição pode gerar uma baixa autoestima na pessoa, a qual sente a necessidade de recorrer a tratamentos médicos, fisioterapêuticos e estéticos.

Destarte, cabe ao esteticista eleger os procedimentos pertinentes para abrandar as estrias, visto que além dos benefícios orgânicos poder-se-á ter efeitos psicológicos. Há vários tratamentos estéticos destinados a esse fim, dentre eles, o eletrolifting que consiste no uso da corrente galvânica aplicada através do eletrodo ativo que promove uma microlesão dérmica. Dessa forma, haverá uma inflamação tecidual localizada que pode possibilitar a regeneração cutânea. (SILVA, ROSA, SILVA, 2017).

O presente estudo se justificou na medida em que 0 uso do eletrolifting pode representar um procedimento ímpar no tratamento das estrias, minimizando transtornos orgânicos e, por consequência, os psicológicos.

Logo, este estudo pode contribuir para que sejam ampliadas as informações concernentes ao emprego e benefício desse tipo de tratamento em pessoa com estrias.

\section{METODOLOGIA DE PESQUISA}

O estudo será baseado em pesquisa bibliográfica explicativa, a qual pode ser caracterizada por ser baseada em livros e bases de dados obtidos na Europa PUC, Pubmed/Medline, Lilacs, Scielo, Scholar Google nos meses de janeiro a junho de 
2019. Para tanto, buscou-se as palavras-chave (descritores): estrias, eletrolifting, microgalvanopuntura.

Será explicativa porque irá "identificar os fatores que determinam ou que contribuem para a ocorrência dos fenômenos" (Gil, 2007, p.42).

Portanto, o estudo buscará investigar os efeitos que o eletrolifting promove no tratamento de estrias.

\section{DESENVOLVIMENTO}

\subsection{ESTRIAS: CONCEITOS E INCIDÊNCIA}

A palavra estria tem sua origem em 1898 , striae distensae, de etimologia latina pode ser traduzida para o português como estria estendida, mas é comumente conhecida apenas como estria. (VAZIN, 2011).

A estria é uma lesão tegumentar adquirida que gera uma atrofia linear paralela acompanhando, na maioria das vezes, às linhas de clivagem da pele. Nela há a diminuição da atividade dos fibroblastos na produção de matriz extracelular de boa qualidade, além de ruptura de fibras já existentes. Esse tipo de lesão elementar da pele tem característica benigna e sua coloração varia segundo a fase evolutiva. Ela representa uma alteração estética na pele que pode causar muito desconforto e até mesmo baixa autoestima e depressão. (MAIA, 2011; VANZIN, 2011).

Sabe-se que a estria tem sua variação de cor de acordo com o tempo de evolução. No inicio, ela tem uma cor rosada a avermelhada e, por isso, é designada de estria rubra (estria rubrae), pois é uma resposta inflamatória associada à vasodilatação. Com sua evolução, a estria tem uma redução da microcirculação resultando em perda de colágeno e de fibras elásticas e como consequência, ela passa apresentar um aspecto rugoso e com coloração esbranquiçada e passa a ser denominada de estria alba. (AGNES, 2017). 
Figura 1: Tipos de estrias.

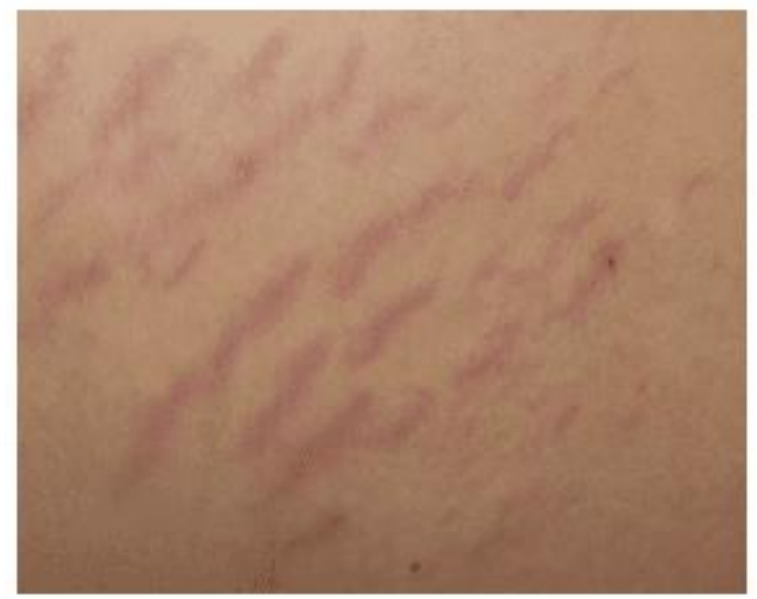

estria rubra

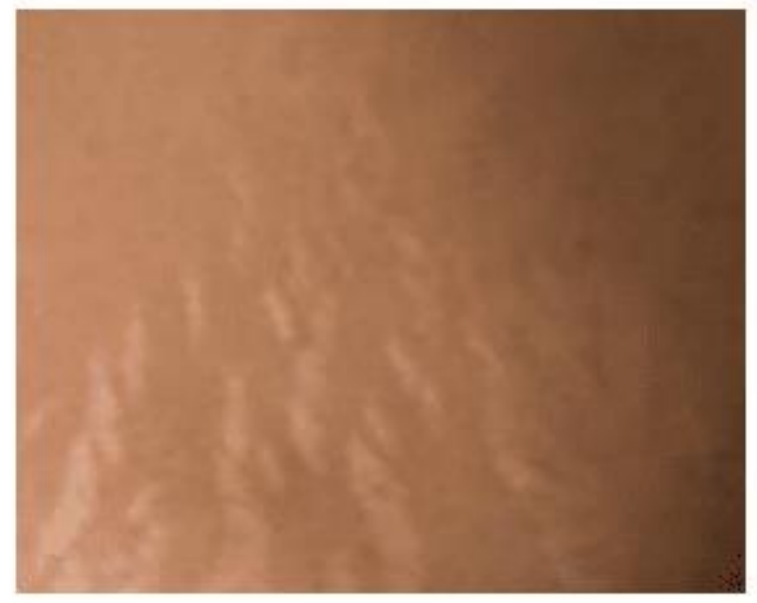

estria alba

Fonte: os autores, 2019.

É mister destacar que as estrias podem aparecer em ambos os sexos, porém há maior incidência nas mulheres (60\%) quanto comparado aos homens (40\%). (SAMPAIO, 2018). Sabe-se que elas são umas das mais ordinárias alterações na estética corporal e podem acometer $90 \%$ das mulheres e $15 \%$ dos homens a partir dos 30 anos. (GUIRRO e GUIRRO, 2004). Elas também são frequentes em gestantes.

\subsection{ESTRIAS: ETIOLOGIA}

Sabe-se que as estrias são atrofias tegumentares adquiridas e sua etiologia básica é idiopática, no entanto, há fatores que contribuem para a sua manifestação, sendo os distúrbios endócrinos o mais determinante. (WHITE et al, 2008). Há outros autores que também frisam os fatores endócrinos como sendo os mais determinantes do aparecimento de estrias, embora afirmem que há muita indefinição etiológica e controvérsias. (BRAVIM e KIMURA, 2007).

No entanto, existem três teorias fundamentais que tentam explicar o aparecimento das estrias, a saber: a teoria mecânica, endocrinológica e infecciosa. (FACUNDO, 2014; WHITE et al, 2008; GUIRRO e GUIRRO, 2004). 
A teoria mecânica explica que o surgimento da estria seria devido ao estiramento excessivo do tegumento e este fato poderia romper a pele e gerar perda de fibras elásticas. As principais causas do estiramento da pele são a obesidade, o estirão do crescimento na puberdade, a hipertrofia muscular excessiva quando se pratica exercício físico, uso prolongado de corticóides e síndrome de Cushing. (FURLANI et al, 2010). Outro fator comum é o estiramento mecânico da pele durante a gravidez. (MAIA et al, 2009).

A teoria endocrinológica explica que o aparecimento da estria pode está relacionado à disfunção hormonal. Sabe-se que o hormônio esteroide interfere na ação dos fibroblastos e o seu desequilíbrio está presente em todas as formas de aparecimento das estrias durante a fase de adolescência, gravidez e obesidade. (BRAVIM e KIMURA, 2007; BONETTI, 2007; GUIRRO e GUIRRO, 2004).

É mister salientar que os hormônios do estresse, a adrenalina, noradrenalina, o hormônio adrenocorticotrófico e os glicocorticoides também são apontados como desencadeantes de estrias associadas à atividade física estressante, bem como apenas estados estressantes. (GUIRRO e GUIRRO, 2004).

A teoria infecciosa é pouco defendida na literatura, contudo há alguns adeptos que acreditam que processos infecciosos podem gerar dados nas fibras elásticas. Esse fato explicaria o aparecimento de estrias em pessoas jovens com febre reumática, tifoide, hepatopatias crônicas e síndrome de Marfan. (FURLANI et al, 2010).

Acredita-se que as estrias também podem ter influência genética onde a expressão dos genes determinantes 24 para formação de colágeno, elastina e fibronectina estaria diminuída em pessoas com estrias atróficas. (FACUNDO, 2014).

Outro fato importante que predispõe o aparecimento das estrias é desidratação cutânea, visto que as peles mais secas têm maior predisposição às estrias. (VANZIN, 2011).

Existe muito pouco estudo concernente a fisiopatologia das estrias da pele e a maioria das pesquisas tem priorizado os fatores etiológicos e os procedimentos de tratamento 
em detrimento do desenvolvimento da doença. Pode ser que a dificuldade na realização de estudos laboratoriais explique a escassez de pesquisas sobre estrias. (CORDEIRO; MORAES, 2009).

As estrias são instaladas quando há uma degeneração cutânea em consequência da diminuição da atividade dos fibroblastos na produção de matriz extracelular e subsequente interrupção de continuidade das fibras existentes. Sabe-se que ao se comparar com a pele saudável, a pele com estria tem menor quantidade de fibrilina, colágeno e elastina. Além disso, a pele com estria tem alteração de coloração devido a disfunções da atividade dos melanócitos e da microcirculação e das reações de defesa do organismo. Quando a estria tem reação inflamatória recente devido ao estiramento excessivo da pele que rompe tanto a pele quanto os capilares é chamada de estria rubra ou rosada. Nesse caso, pode haver quadro de dor e até mesmo prurido intenso. Já as estrias albas ou brancas ou nacaradas têm além da ruptura das fibras elásticas e colágenas, lesões fibróticas, disfunção nas glândulas sudoríparas e sebáceas e no desenvolvimento dos pelos. Elas ainda podem ser estrias atróficas que possuem desorganização das fibras, uma característica hipocrômica, contudo com preservação dos anexos da pele. (BRAIT, 2018).

\subsection{ELETROLIFTING: BENEFÍCIOS MORFOFUNCIONAIS}

É sabido que o aspecto inestético que as estrias geram pode causar impactos emocionais, além de físicos e por isso, muitos procuram por tratamentos estéticos para minimizar e até mesmo prevenir o aparecimento de estrias.

É imperativo ressalvar que há um arsenal cosmetológico e vários equipamentos que de forma isolada ou associada são utilizados para tratar pessoas com estrias e dentre eles, o eletrolifting.

O eletrolifting é um procedimento de tratamento que foi desenvolvido pelo médico dermatologista francês Humberto Pierantoni, em 1952, para preenchimento de sulcos e estrias. Essa técnica também é conhecida como galvanopuntura ou microgalvanopuntura e consiste numa técnica que utiliza a corrente galvânica na 
ordem de alguns microampères $(\mu \mathrm{A})$, ou seja, microgalvânica, sendo que o eletrodo com ou sem a agulha (eletrodo ativo) sempre deverá ser conectado ao polo negativo. Pierantoni observou que a estimulação elétrica permitia a atenuação dos sulcos e estrias. (DAL GOBBO, 2010).

É sabido que o eletrolifting tem seus efeitos fisiológicos distribuídos em quatro fenômenos: eletroquímicos, osmóticos, vasomotores e alteração na excitabilidade celular. (Bragato, Fornazari e Deon, 2013). A estimulação na pele promoverá hiperemia ativa e aumentará o quantitativo de fibroblastos jovens, promoverá a migração de queratinócitos e macrófagos e desenvolverá a neovascularização e, desta forma, regenerará o tecido subepidérmico. (DAL GOBBO, 2010).

Essa técnica pode ser obtida através de uma corrente galvânica que irá gerar um processo inflamatório na pele e estimulará uma regeneração tecidual, pois o trauma promovido pela agulha junto com a corrente elétrica promoverá o aumento do metabolismo para recomposição de tecido colagenoso, o qual poderá preencher a área tratada. (SILVA, ROSA e SILVA, 2017).

É sabido que o eletrolifting deverá provocar uma pequena lesão na pele que irá resultar em edema e hiperemia que surgem devido à liberação de mediadores químicos vasodilatadores. A lesão passa a ser preenchida por um exsudato inflamatório mesclado de leucócitos, eritrócitos, proteínas plasmáticas e fáscias de fibrina. Tem-se de forma simultânea a epitelização da área lesionada e, desta forma, células epidérmicas passam a invadir o local no qual foi feita a inserção da agulha ou da ponteira. Um dos fenômenos que estimulam a invasão das células epidérmicas é a formação de fibrina originada pela hemorragia da microlesão. Haverá também o aumento do número de fibroblastos jovens na região, além de uma nova microcirculação e do retorno da sensibilidade álgica devido à reparação tecidual que podem fechar as estrias e dar uma melhor aparência da pele. (SANTOS e OGATA, 2012).

Em uma dissertação de mestrado em biologia celular e molecular realizado na Pontifícia Universidade Católica do Rio Grande do Sul intitulado "Tratamento de 
estrias albas com galvanopuntura: benéfico para estética, estresse oxidativo e perfil lipídico" se pode constatar os benefícios deste tratamento. O estudo consistiu em aplicar o eletrolifting em estrias albas nos glúteos de 32 voluntárias com faixa etária média de 25 anos, uma vez por semana ao longo de um período de dez semanas. Foi coletado sangue venoso antes e após as sessões e feita à análise das concentrações plasmáticas de PCR, TNF- $\alpha$, NO, TBARS, LDL-C oxidada, HDL-C, colesterol total, CAT e ácido úrico. O resultado da análise bioquímica das amostras de sangue determinou que a galvanopuntura não induz nenhum processo inflamatório sistêmico, porém diminui admiravelmente o estresse oxidativo. Visto que a análise dos níveis de concentração plasmática constatou que a concentração de colesterol total não se alterou, enquanto as HDL (lipoproteínas de alta densidade) aumentaram e a oxidação das LDL (lipoproteínas de baixa densidade) diminuíram, ou seja, houve a proteção dos lipídios plasmáticos da lesão oxidativa sem resposta inflamatória sistêmica. Portanto, os dados apresentados no estudo indicaram que o eletrolifting tem um efeito antioxidante e antidislipidêmico. (BITENCOURT, 2007).

Existem estudos que relatam resultados satisfatórios no tratamento das estrias com o uso do eletrolifting. Um desses estudos foi realizado com o objetivo de avaliar os efeitos do microagulhamento em relação à microgalvanopuntura no tratamento de estrias atróficas. Para tanto, foi realizada uma pesquisa quase-experimental não controlada, na qual participaram 10 voluntárias com idades de 20 a 44 anos com estrias atróficas. Foram feitas uma avaliação fotográfica e uma planificação clássica e digitalizada, além de um questionário subjetivo para a análise da sensação de melhora. As voluntárias foram tratadas 1 vez por semana durante 4 meses e receberam as técnicas de microgalvanopuntura no lado direito e microagulhamento no lado esquerdo. O estudo concluiu que houve melhora com ambas as técnicas e sem diferença significativa entre elas e na satisfação das voluntárias. (SILVA, ROSA, SILVA, 2017).

Outro estudo intitulado "Comparativo entre galvanopuntura e microagulhamento" teve como objetivo geral avaliar o efeito da corrente galvânica e do microagulhamento. Para comparar foi aplicado o microagulhamento para tratar estrias no glúteo direito e 
eletrolifting no glúteo esquerdo de apenas uma voluntária, de 31 anos com fototipo IV e sem ter passado por intervenções estéticas na área. $O$ estudo teve caráter qualitativo e foi realizado na Universidade Tiradentes, Aracaju-SE. A voluntária assinou o termo de consentimento livre e esclarecido e passou por uma anamnese, além de ter sido fotografada a região antes e durante a evolução do tratamento. Para a aplicação da galvanopuntura foi usado o Neurodyn Esthetic, Ibramed com intensidade de $100 \mu \mathrm{A}$ e com a técnica de perfurar a epiderme em linha reta no sentido da estria levantando-a por 3 segundos e com tratamento semanal. Já para o microagulhamento o FDR Derma Roller com 540 agulhas de $0,5 \mathrm{~cm}$ com a técnica de 15 movimentos verticais, horizontais e diagonais direita e esquerda, sendo o tratamento realizado duas vezes ao mês num total de quatro sessões. $O$ estudo concluiu que a galvanopuntura foi mais eficiente quando comparado ao microagulhamento, pois na segunda sessão já houve melhora na aparência da estria, porém quinta sessão a evolução foi estagnada. Já com o microagulhamento não foi constatada nenhuma diferença nas estrias. (SILVA et al, 2016).

Sabe-se que o tratamento de estrias albas necessita uma intervenção mais agressiva, como o eletrolifting. A fim de avaliar a eficácia do eletrolifting na melhora da aparência e da sensibilidade de estrias albas da região glútea foi realizado um estudo quase experimental em voluntárias. O estudo foi aprovado pelo Comitê de Ética em Pesquisa da Faculdade Ciências Médicas de Minas Gerais e as voluntárias assinaram o Termo de Consentimento Livre e Esclarecido. As seis voluntárias saudáveis possuíam idades de 18 a 28 anos com fototipos II, III e IV e foram submetidas a uma avaliação através de uma entrevista e um questionário adaptado por Guirro para avaliação das estrias. Elas foram expostas a uma sessão por semana num total de seis semanas com duração de trinta minutos. O aparelho utilizado foi STIMULUS FACE da marca HTM e foi realizada a punturação com agulha descartável de três milímetros e com intensidade de $150 \mu \mathrm{A}$ nas duas primeiras sessões e $100 \mu \mathrm{A}$ nas quatro seguintes. Constatou-se que $34 \%$ da amostra não tiveram melhora significativa e $66 \%$ obtiveram melhora moderada a acentuada na aparência das estrias. Quanto à escala de dor, confirmou-se uma melhora da sensibilidade através de avaliação com estesiômetro e quanto ao grau de satisfação, $83,3 \%$ das voluntárias ficaram satisfeitas ou muito 
satisfeitas com o tratamento. Pode-se inferir que o eletrolifting promoveu um tratamento satisfatório e como melhora no aspecto visual das estrias, além de melhorar a sensibilidade local. (COSTA e SILVA, 2018).

Uma pesquisa de ensaio clínico randomizado com cegamento intitulado "Estudo comparativo entre a galvanopuntura e a escarificação no tratamento das estrias atróficas brancas em mulheres entre 20 e 25 anos" foi aprovada pelo Comitê de Ética no UniSALESIANO e submetida à Plataforma Brasil do Ministério da Saúde e teve como objetivo verificar os efeitos das técnicas galvanopuntura e a escarificação no tratamento das estrias atróficas brancas. Esse experimento foi realizado com seis voluntárias com idade entre 20 e 25 anos que possuíam estrias brancas na região glútea na Clínica Corpo e Essência na cidade de Lins/SP durante três meses. O acompanhamento foi feito através de inspeção e palpação, registros fotográficos antes e após tratamento. As voluntárias foram divididas em dois grupos: grupo galvanopuntura e grupo de escarificação. $O$ grupo galvanopuntura realizou 8 sessões de tratamento com Striat da marca lbramed, com intensidade de $160 \mu \mathrm{A}$ e agulhas estéreis. Já o grupo de escarificação foi feita a técnica de raspagem superficial em todo o comprimento das estrias, a fim de proporcionar uma inflamação local e posterior reparo da pele. Esse grupo foi submetido a 8 sessões, porém 2 voluntárias só receberam 5 sessões, pois tiveram intercorrências durante o tratamento. $O$ resultado da pesquisa destacou que a galvanopuntura foi mais eficaz do que a escarificação, pois esta última resultou em limitações que interferiram no cronograma da pesquisa e nos resultados. (PEDRO, AUGUSTO e OLIVEIRA, 2015).

A monografia "Utilização do eletrolifting e da carboxiterapia para tratamentos de estrias" objetivou contextualizar a ação do eletrolifting e da carboxiterapia e como recursos fisioterapêuticos para o tratamento de estrias. Esse estudo foi desenvolvido através de revisão bibliográfica e permitiu concluir que tanto o eletrolifting quanto a carboxiterapia causam efeitos eficazes no tratamento das estrias. (FACUNDO, 2014).

Outra monografia denominada "Principais métodos para tratamento estético de estrias" objetivou analisar quais os procedimentos estéticos mais relatados na literatura para tratar estrias, discutir as vantagens destes procedimentos e os métodos 
de maior escolha. Esse estudo foi realizado através de revisão de literatura que abordou como procedimentos estéticos a galvanopuntura, a microdermoabrasão, peeling químico, uso de cosmecêuticos, de silício orgânico e de aspartato de hidroxiprolina-metilsilanol. A autora concluiu que a estria tem sua aparência melhorada em relação a sua espessura/largura e coloração quando a pessoa é submetida à galvanopuntura, microdermoabrasão e peelings associados ao uso de cosmecêuticos. Relatou que as técnicas citadas também podem ser associadas ao peeling químico e cabe ao profissional avaliar e indicar o tratamento mais apropriado. (COSTA, 2016).

Outro estudo que comprou a eficácia do eletrolifting foi realizado com uma voluntária de 30 anos, sedentária, nulípara, pele morena clara, sem históricos de cardiopatia e que fazia uso de anticoncepcional oral. A técnica foi aplicada em 10 sessões na região lombossacra com o aparelho STRIAT (IBRAMED). Do lado direito foi aplicada a técnica de punturação com a corrente passando e do outro lado aplicou-se a punturação com o equipamento desligado, ou seja, não passando nenhum tipo de corrente. Os registrou fotográficos comprovaram a melhora do aspecto visual da estria no lado tratado com a corrente passando. (GALDINO, DIAS e CAIXETA, 2010).

O estudo "Uso do eletrolifting para melhorar a aparência da pele" objetivou analisar por meio de revisão bibliográfica o efeito da utilização de eletrolifting sobre a pele. Após a análise de 20 artigos foi possível contatar que sete artigos relatavam os benefícios para a renovação celular, ativação do colágeno e elastina, abrandamento da profundidade e comprimento das rítides e linhas de expressão, proporcionando, portanto, maior autoestima e qualidade de vida dos clientes. Outros onze estudos acrescentaram que o eletrolifting causa a dissimulação parcial ou total das rítides e onze artigos afirmavam que o eletrolifting é um excelente tratamento de estrias. Dois artigos não associam o eletrolifting à utilização de cosméticos, mas outros dezoitos o fizeram e afirmaram que a associação melhorar o aspecto geral da pele. (OGLIARI et al, 2016).

Um estudo exploratório, experimental, de abordagem quantitativa e qualitativa foi desenvolvido sobre dois protocolos de eletrolifting para o tratamento de estrias albas 
que surgiram no período gestacional utilizando a corrente microgalvânica e verificando seus efeitos. Participaram 26 voluntárias com faixa etária entre 20 e 35 anos. As participantes foram divididas em dois grupos e fizeram 15 sessões com 12 dias de intervalo entre elas e com intensidade de $100 \mu \mathrm{A}$. O grupo A foi tratado pela punturação longitudinal e o grupo B pela punturação transversal. Como critério de avaliação foi respondido o questionário sobre a intensidade da dor, tipo de dor e a satisfação com o tratamento, além de ser feita uma avaliação fisioterapêutica no início, após a quinta, décima e décima quinta sessão. As estrias foram fotografadas e sua área, comprimento e largura foram analisadas por meio do software ImageJ, da planimetria manual e da paquimetria. É bom ressaltar que o grupo A teve melhora significativa em apenas 5 sessões enquanto o grupo $B$ demorou 15 sessões para apresentar resultado semelhante. Todavia, o resultado ao final do tratamento foi semelhante na redução do tamanho das estrias e no grau de satisfação. (SILVEIRA, 2016).

\subsection{ELETROLIFTING: TÉCNICAS}

O tratamento é feito com o uso de um aparelho (figura 2) que produz corrente galvânica com microamperagem com emprego de dois tipos de eletrodos: um negativo, tipo caneta, que irá entrar em contato direto com a área a ser tratada e outro positivo, de borracha e esponja, que irá fechar o circuito elétrico. (DAL GOBBO, 2010). Logo, não há necessidade de o cliente retirar objetos metálicos durante o tratamento, tais como: anéis, relógios, brincos ou pulseiras. (BAENA, 2003 apud FACUNDO, 2014). 
Figura 2: Modelos de aparelho que permitem a aplicação do eletrolifting.
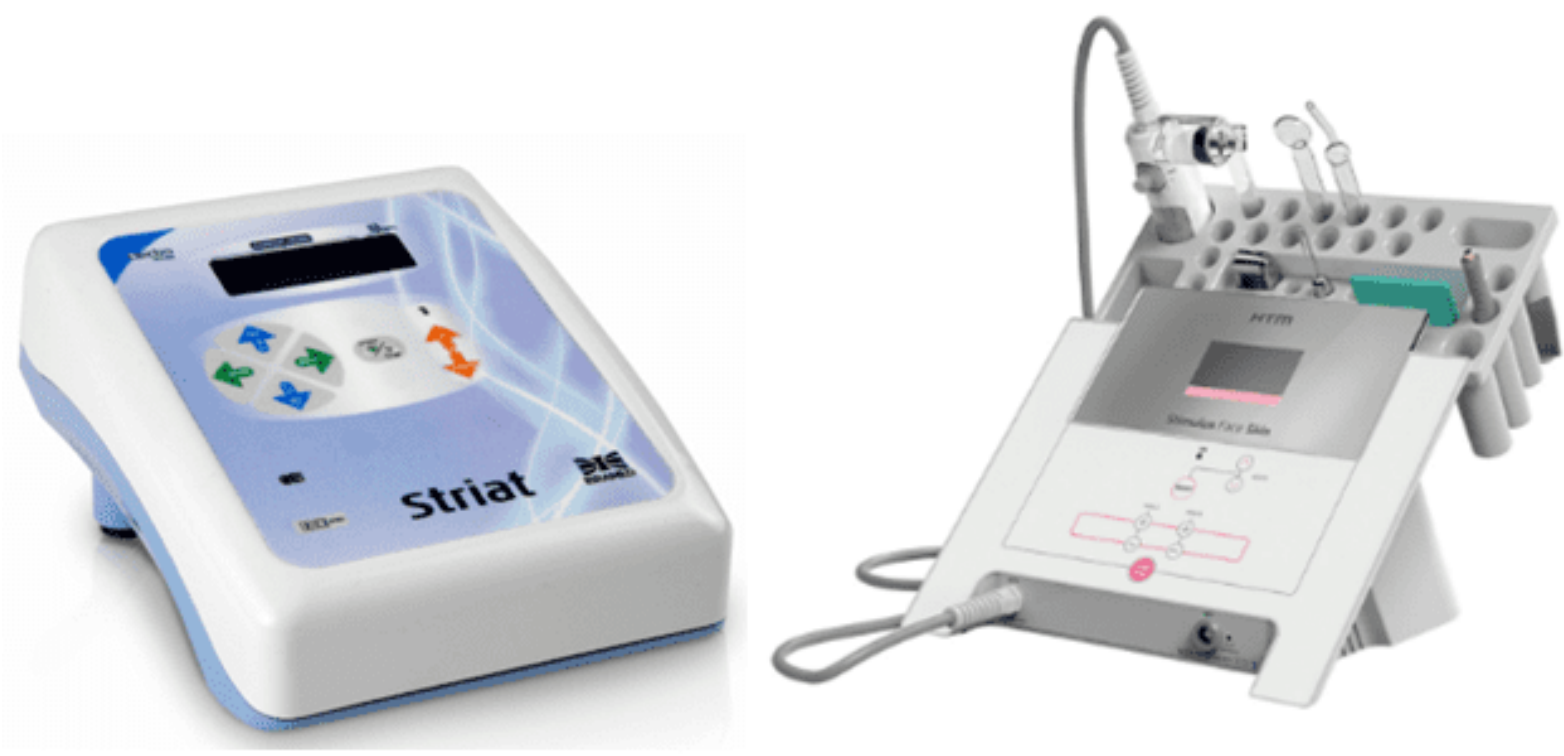

Fonte: os autores, 2019.

A aplicação do eletrolifting pode ser dividida em duas técnicas principais: uma que utiliza a ponteira de eletrolifting (figura 3) e a outra a que utiliza agulha estéril descartável (figura 4).

Figura 3: Ponteira de eletrolifting.

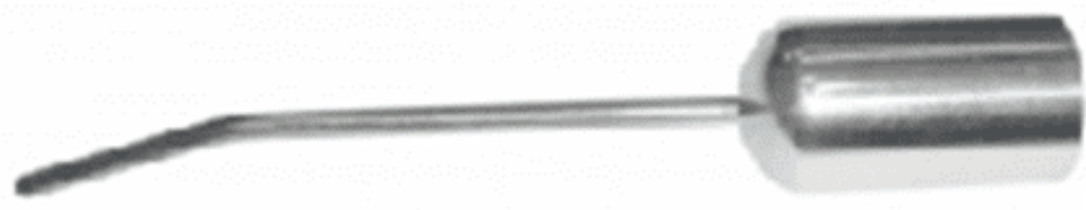

Fonte: os autores, 2019. 
Figura 4: Agulha de eletrolifting.

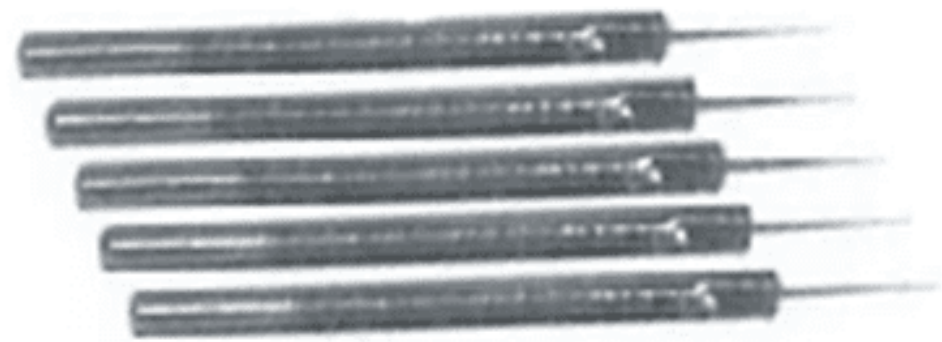

Fonte: os autores, 2019.

Na primeira técnica, usa-se o eletrolifting com agulha (figura 5) e é bem mais agressiva e neste caso usa-se sempre uma agulha estéril e descartável ao invés da ponteira eletrolifting. Essa agulha deve ser fina, resistente e pontiaguda, construída em material inoxidável e com comprimento máximo de $4 \mathrm{~mm}$ a fim de penetrar com facilidade na pele. (BORGES, 2010).

Já a segunda técnica, usa-se uma ponteira de eletrolifting (figura 6) estéril fixada a caneta que corresponde ao eletrodo negativo (ativo) e deverá ser arranhada a estria ao logo de toda região afetada até que haja hiperemia. O eletrodo positivo (passivo) deverá estar próximo a região a ser tratada para fechar o campo elétrico. Essa técnica é menos agressiva e mais tolerável pelos clientes. 
Figura 5: Eletrolifting com agulha.

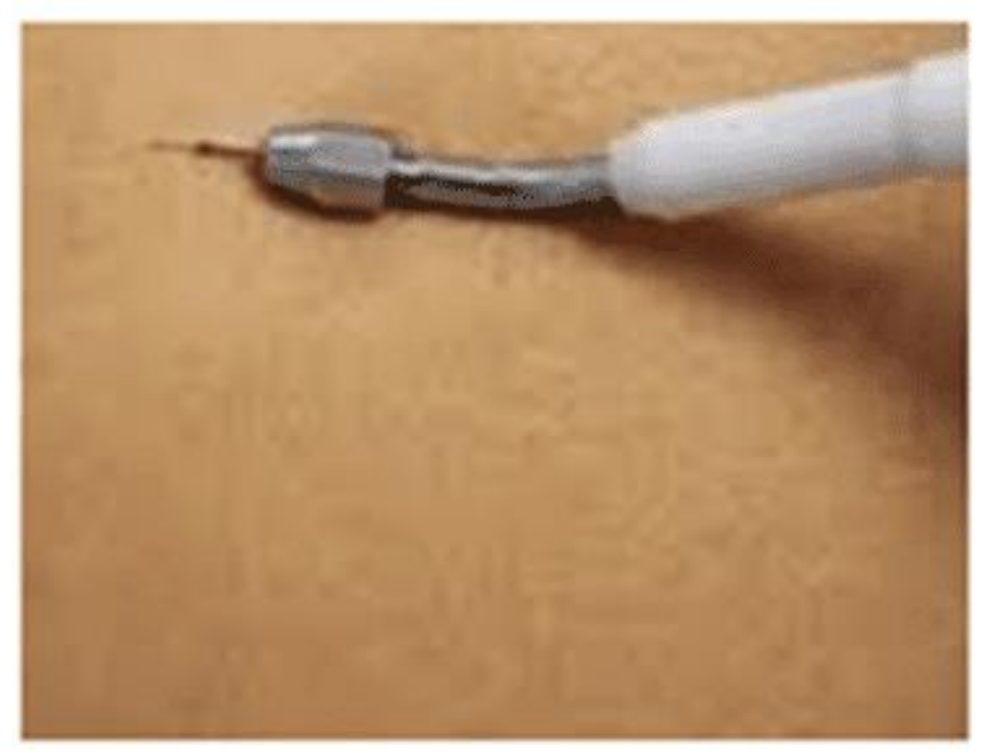

Fonte: os autores, 2019.

Figura 6: Eletrolifting com ponteira.

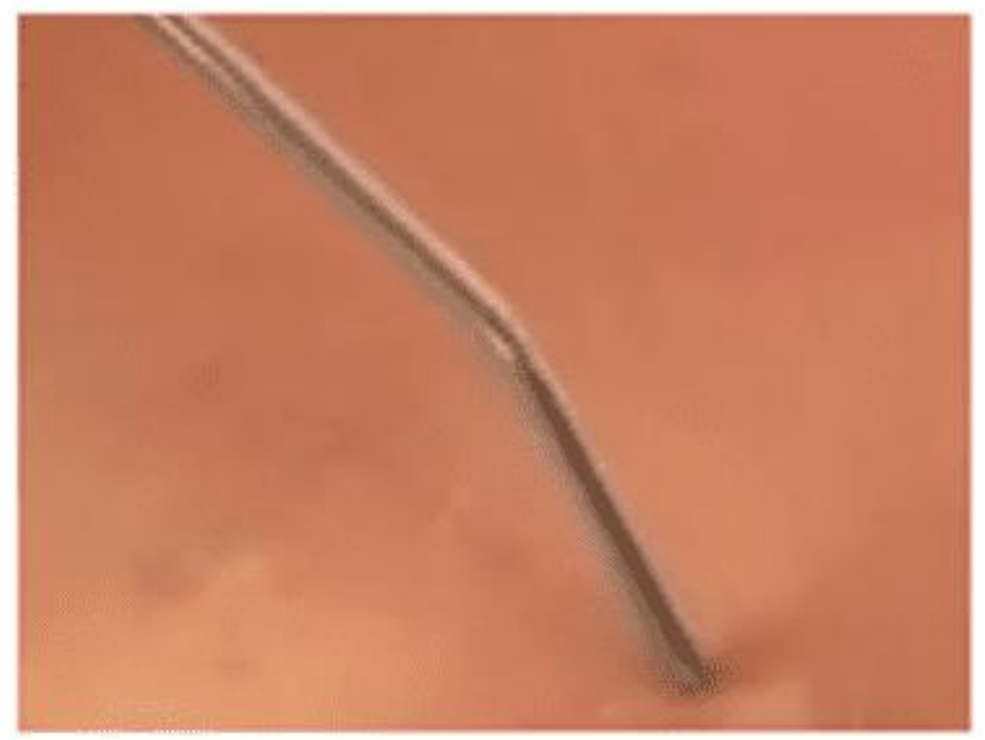

Fonte: os autores, 2019.

Há 3 modalidades de aplicação, a saber (DAL GOBBO, 2010; GUIRRO e GUIRRO, 2004 apud FACUNDO (2014):

RC: 34635

Disponível em: https://www.nucleodoconhecimento.com.br/saude/tratamento-de-estrias 
- Pontual ou puntura consiste a introdução da agulha em pontos adjacentes e dentro da estria e não se poderá repetir a penetração da agulha no mesmo ponto. Além de se dá um intervalo mínimo de 15 dias para nova aplicação na área.

- Deslizamento consiste no deslizamento da agulha paralela à estria e o tratamento poderá ser semanal;

- Escarificação, a agulha será deslizada (riscada) nas estrias, porém deverá ser posicionada a noventa graus, ocasionando uma lesão do tecido. (REBONATO et al, 2012).

Há profissionais que dividem a técnica de aplicação do eletrolifting com agulha em quatro formas de aplicação. (RUSENHACK, 2004):

1. De forma puntiforme ou punturação sendo que a agulha deverá ser introduzida na pele verticalmente na estria em toda extensão do sulco com profundidade de perto $1 \mathrm{~mm}$. Essa técnica tem sido considerada a mais aconselhada, apesar de ser incômoda e nela são feitas várias inserções da agulha na mesma estria. (MEYER et al, 2009);

2. De forma linear em que a agulha é introduzida obliquamente à estria com movimentos circulares de levantamento e com profundidade de cerca de 2 a 3 $\mathrm{mm}$;

3. De forma angulada ou "escama de peixe", neste caso a agulha é inserida sobre as bordas da estria, alternando-se os lados de forma oblíqua, sendo facultativo o levantamento da pele;

4. De forma transversal, em que a agulha precisará erguer toda a superfície da estria, indo de uma borda à outra da pele, sem, contudo, adentrar aquém da epiderme. A permanência da elevação da pele por cerca de 2 segundos, aumentará a resposta almejada.

É bom ressaltar que as técnicas poderão ser aplicadas isolada ou associadamente dependendo da profundidade, extensão, textura da pele e área a ser tratada. 
É necessário frisar que o eletrolifting emprega uma corrente de intensidade reduzida a microamperagem e quanto menor o tamanho do eletrodo, menor será a intensidade máxima tolerável e vice-versa. (BORGES, 2010). Não existe um consenso sobre a intensidade da aplicação do eletrolifting e este fato pode ser comprovado quando se analisa a tabela 1 que foi um dos resultados da dissertação de Mestrado em Profissional em Engenharia Biomédica do Programa de Pós-Graduação em Engenharia Biomédica da Universidade Tecnológica Federal do Paraná. Na tabela 1 a intensidade varia de 50 até 150 microampéres. (SILVEIRA, 2016).

Tabela 1 - Intensidade, intervalo e números de sessões comumente utilizadas em estudos envolvendo a corrente microgalvânica no tratamento de estrias.

\begin{tabular}{|c|c|c|c|c|c|c|}
\hline Autores & Tipo de estudo & $\begin{array}{c}\text { Populaç } \\
\text { ão }\end{array}$ & $\begin{array}{l}\text { Região } \\
\text { tratada }\end{array}$ & $\begin{array}{c}\mathrm{N}^{0} \mathrm{de} \\
\text { sessōes }\end{array}$ & $\begin{array}{l}\text { Intervalo } \\
\text { entre } \\
\text { sessōes }\end{array}$ & $\begin{array}{l}\text { Intensidad } \\
\text { e da } \\
\text { corrente }\end{array}$ \\
\hline $\begin{array}{l}\text { White et al. } \\
2008\end{array}$ & $\begin{array}{l}\text { Quantitativo } \\
\text { exploratório e } \\
\text { experimental }\end{array}$ & 01 & $\begin{array}{l}\text { Lateral } \\
\text { direita da } \\
\text { pelve }\end{array}$ & 20 & 7 dias & $\begin{array}{l}70 \text { e } 100 \\
\mu \mathrm{A}\end{array}$ \\
\hline $\begin{array}{l}\text { Meyer et al. } \\
2009\end{array}$ & Experimental & 01 & $\begin{array}{l}\text { Lateral } \\
\text { esquerda } \\
\text { da pelve }\end{array}$ & 07 & 7 dias & $\begin{array}{l}\text { Não } \\
\text { informado }\end{array}$ \\
\hline $\begin{array}{l}\text { Galdino et al. } \\
2010\end{array}$ & Experimental & 01 & $\begin{array}{l}\text { Lombossac } \\
\text { ra direita }\end{array}$ & 10 & 7 dias & $100 \mu \mathrm{A}$ \\
\hline $\begin{array}{l}\text { Silva et al. } \\
2010\end{array}$ & Experimental & 03 & $\begin{array}{l}\text { Abdome, } \\
\text { axila e coxa }\end{array}$ & 10 & 7 dias & $\begin{array}{l}50,100 \mathrm{e} \\
150 \mu \mathrm{A}\end{array}$ \\
\hline $\begin{array}{l}\text { Campos et al. } \\
2012\end{array}$ & Não informado & 07 & Glúteos & 10 & 7 dias & $\begin{array}{l}50,100 \mathrm{e} \\
150 \mu \mathrm{A}\end{array}$ \\
\hline $\begin{array}{l}\text { Oliveira et al. } \\
2012\end{array}$ & Estudo de caso & 01 & Abdome & 04 & 7 dias & $100 \mu \mathrm{A}$ \\
\hline $\begin{array}{l}\text { Rebonato et al. } \\
2012\end{array}$ & $\begin{array}{l}\text { Ensaio clinico } \\
\text { controlado }\end{array}$ & 10 & $\begin{array}{l}\text { Glúteos e } \\
\text { quadril }\end{array}$ & 10 & $\begin{array}{l}\text { Mínimo } \\
\text { de } 7 \text { dias }\end{array}$ & $\begin{array}{l}50,100 \mathrm{e} \\
150 \mu \mathrm{A}\end{array}$ \\
\hline $\begin{array}{l}\text { Oliveira et al. } \\
2013\end{array}$ & Ensaio clinico & 03 & Abdome & 04 & 7 dias & $100 \mu \mathrm{A}$ \\
\hline Wathier, 2013 & Estudo de caso & 01 & Glúteos & 04 & 7 dias & $\begin{array}{l}80 \text { a } 100 \\
\mu \mathrm{A}\end{array}$ \\
\hline
\end{tabular}

Fonte: SILVEIRA, 2016.

No entanto, é sabido que a intensidade ideal para tratamento de estrias varia de $70 \mathrm{a}$ $100 \mu \mathrm{A}$, porém variar segundo a sensibilidade do cliente. (GUIRRO e GUIRRO, 2004). Porém, a intensidade da corrente prescrita na prática, a partir da literatura vigente, 
pode variar de 50 a $100 \mu \mathrm{A}$ ao se aplicar a punturação ou até $150 \mu \mathrm{A}$ na técnica de escarificação. (SILVEIRA, 2016).

A intensidade também pode variar de acordo com a disfunção da pele, sendo que para o tratamento de estrias é entre 70 a 100 microampéres e para rítides é de 150 a 200 microampéres, todavia se reitera que os valores de intensidade vão variar de acordo com a sensibilidade de cada cliente. (BORGES, 2010). É mister ressaltar que a intensidade da microcorrente é determinada pela sensibilidade do cliente, portanto, ela deve respeitar o limiar de dor do cliente. (SILVEIRA, 2016). Por isso, o esteticista deverá testar cada área a ser tratada para se certificar da tolerância do cliente, pois cada região do corpo poderá ter diferente nível de sensibilidade a corrente. (DAL GOBBO, 2010).

Para alguns fisioterapeutas a intensidade não deveria ser superior a $300 \mu \mathrm{A}$ a fim de prevenir possíveis lesões ou manchas na pele devido à intensa ação do componente galvânico. (BROGES, 2010). Há aqueles que recomendam que melhores resultados podem ser alcançados com intensidades entre 150 a $300 \mu$ A. (AGNES, 2017).

Sabe-se que esse tipo de eletroterapia possui uma corrente contínua de baixa intensidade (microampéres), por isso, não há efeito inflamatório sistêmico, tanto agudo quanto crônico, durante o tratamento. Esse fato foi comprovado por estudos e exame de sangue que dosaram os marcadores de inflamação sistêmica, os níveis plasmáticos de TNF- $\alpha$ e PCR, antes do tratamento, 24h após a primeira sessão (dia 1), antes da última sessão (dia 70) e 24h após a última sessão (dia 71) de 32 voluntárias entre 20 e 30 anos com estrias alba na região glútea. O estudo concluiu que não houve diferenças significativas nesses parâmetros inflamatórios. O mediador inflamatório multifacetado, óxido nítrico, apresentou uma diminuição discreta mas não significativa após as primeiras 24 h. (BITENCOURT, 2007).

No entanto, as pessoas com pele alípica podem apresentar ausência de sensibilidade à corrente durante as primeiras sessões, visto que a resistência da pele a passagem de corrente está aumentada. (GUIRRO e GUIRRO, 2004; BARBOSA e CAMPOS, 2013). 
Para se obter um resultado favorável é necessária uma avaliação prévia a fim de determinar o tipo de estria, tamanho da estria, espessura da pele, cor da pele, idade e exclusão de contraindicações e desta forma poder-se-á determinar o número de sessões e a intensidade da corrente. Todavia, é bom frisar que esse tipo de tratamento ainda não possui um protocolo específico em relação ao estímulo, frequência, intensidade, tempo e a sequência do tratamento. (GUIRRO e GUIRRO, 2004).

Antes de se aplicar o eletrolifting, deve-se higienizar a área a ser tratada, para tanto é possível usar sabonete e água para remoção de impurezas ou mesmo o aparelho de alta frequência com os eletrodos cebolão, cebolinha ou rolinho. (DAL GOBBO, 2010).

Após a aplicação do eletrolifting é preciso manter a pele bem hidratada, além de se fazer o controle da oleosidade a fim de melhor a resposta de reparação tecidual. É bom o uso de despigmentante à noite e de protetor solar com FPS acima de 30 ao longo do dia, reaplicado-o a cada três horas. É importante que após o tratamento se evite a exposição solar para se prevenir a formação de hipercromias, mesmo se usando protetores solares. Pode ser aplicado após tratamento imediato cosméticos antioxidantes como vitamina $\mathrm{C}$ e fatores de crescimento a fim de estimular a produção do colágeno. (SILVA et al, 2018).

O eletrolifting melhora a aparência da estria, pois diminui a espessura/largura e coloração e pode evitar o surgimento de novas estrias. Ela pode ser aplicada isoladamente ou em associação a outras técnicas de tratamento, tais como: microdermoabrasão e peelings associados ao uso de cosmecêuticos. (JUNIOR et al, 2013).

Todavia, há profissionais que não recomendam associação do eletrolifting a outros tratamentos estéticos, pois afirmam que pode gerar uma ação anti-inflamatória, todavia recomendam o uso de protetores solares afim de prevenir as discromias na pele (BORGES, 2006 apud SILVA et al, 2018). 
Contudo, a resposta ao tratamento vai variar de pessoa a pessoa, pois dependerá da faixa etária, sexo, condições físicas e nutricionais, tipo e grau da estria, no entanto é sabido que as estrias mais recentes irão responder melhor ao tratamento.

Há profissionais que preconizam que as sessões para tratamento de estrias deverão ter intervalos de uma semana entre as aplicações e que os resultados podem ser constatados entre cinco a quinze sessões. (BROGES, 2010). A literatura vigente preconiza que o intervalo entre as sessões pode variar de dois e sete dias. (WHITE et al, 2008; OLIVEIRA, 2013). No entanto, não é aconselhado repetir o tratamento antes que todo processo inflamatório seja reabsorvido.

É preciso ressaltar que o profissional que irá prescrever o eletrolifting deve ser qualificado para aplicá-lo atendendo todas as normas de biossegurança e saiba orientar os clientes quanto às condutas de homecare.

\subsection{ELETROLIFTING: INDICAÇÕES E CONTRAINDICAÇÕES}

O eletrolifting é aconselhado para 0 tratamento de estrias, rítides e marcas de expressão. $\mathrm{Na}$ face, ele é indicado para diminuir as linhas de expressão, sulcos nasogenianos, rítides na glabela, perioculares e na região frontal, típicas do processo de envelhecimento. Ele também é indicado para se obter o efeito drug delivery que consiste na permeação de fármacos na pele através dessa técnica. Os ativos cosmetológicos podem ser associados após a aplicação do eletrolifting, entretanto se deve ter um bom conhecimento da substância usada, pois não poderá conter nenhuma ação antiinflamatória para não anular os benefícios do tratamento.

Além das indicações anteriormente citadas, o eletrolifting também pode ser recomendado em tratamentos de hidratação; nutrição e revitalização; seborreia e edema. (OLIVEIRA, 2014 apud SILVA et al, 2018).

As principais contraindicações são as mesmas para a maioria dos tratamentos eletroterapêuticos, tais como: gestantes, pessoas com diabetes, neoplasias, portadores de marca-passo, problemas cardíacos e epilepsia. Também não é indicado 
para pessoas com hemofilia, vitiligo, síndrome de Cushing, tendência a queloides e uso de medicações a base de esteroides e corticosteroides. (VENTURA, 2003; BORGES, 2010).

Além de gestante, também não é indicado o tratamento de eletrolifting após o parto, devendo ser respeitado o retorno normal dos níveis hormonais anteriores a gestação (AGNE, 2017).

Como não se têm estudos suficientes para indicar o emprego do eletrolifting durante a puberdade, recomenda-se não utilizar, pois é um período de grandes alterações hormonais. Sendo que alguns autores acreditam inclusive que pode ser uma das etiologias do aparecimento das estrias. (WHITE et al, 2008; BORGES, 2010).

O fato de não existir protocolos definidos concernentes ao tipo de estímulo, frequência e intensidade ideal, tempo e sequência do tratamento tem limitado o tratamento de estrias. O melhor resultado poderia ser obtido com a interação dos métodos e com protocolos definidos. Todavia, mesmo sem protocolos definidos, é apropriado garantir que o uso do eletrolifting traz evidentes melhoras ao aspecto da pele tratada. (MATOS; COSTA, 2019).

\section{CONSIDERAÇÕES FINAIS}

O aparelho de eletrolifting é utilizado no tratamento de estrias e outras alterações da pele. Sendo que a estria é um tipo de atrofia tegumentar adquirida e possui etiologia idiopática, porém algumas teorias têm sido sustentadas, tais como: mecânica, endocrinológica e infecciosa. Além disso, elas podem se classificadas em estrias rubras e albas e ambas podem ser submetidas ao tratamento estético.

O eletrolifting é um procedimento que trata as estrias e permite benefícios ímpares, tais como: neovascularização, amplia o número de fibroblastos jovens aumentando a síntese proteica, além de facilitar a migração de queratinócitos e macrófagos, tem efeito antioxidante e antidislipidêmico que resulta na reparação tissular e minimiza o aspecto da estria. 
As técnicas de aplicação são duas: uma utiliza a ponteira de eletrolifting, sendo esta a menos utilizada e outra que utiliza a agulha de cerca de $4 \mathrm{~mm}$. A aplicação da agulha pode ser feita de forma pontual, por deslizamento e por escarificação. Os estudos referenciados nesta pesquisa não demonstraram diferença significativa entre as quatro técnicas de aplicação com a agulha, porém há menos eficácia quando se emprega a ponteira de eletrolifting.

A indicação do eletrolifting é para tratar diferentes tipos de estrias, mas também é indicada para tratamentos de hidratação, nutrição e revitalização, seborréia, edema, rítides, marcas de expressão e efeito drug delivery.

Já as contraindicações seguem as mesmas de outros procedimentos eletroterapêuticos, ou seja, não deve ser aplicado em diabético, epilético, pessoas problema cardíaco e marca-passo cardíaco, distúrbios de sensibilidade, pessoa com câncer, gestante, hemofilia, vitiligo, síndrome de Cushing, tendência a queloides e uso de medicações a base de esteroides e corticosteroides.

Conclui-se que o eletrolifting pode agregar valor aos procedimentos estéticos e fisioterapêuticos, conquanto não seja o único procedimento a ser empregado e sim parte de um conjunto de estratégias terapêuticas. Constatou-se a carência de estudos atualizados concernentes ao tema abordado e recomenda-se que novos estudos sejam implementados para verificar outras aplicabilidades desse recurso terapêutico e estético.

\section{REFERÊNCIAS}

AGNE, J. E. Eletrotermofototerapia. 4. ed. Rio Grande do Sul: Editorial Santa Maria, 2017.

BARBOSA, D. F.; CAMPOS, L. G. Os efeitos da corrente galvânica através da técnica de eletrolifiting no tratamento do envelhecimento facial. Revista Inspirar, Movimento \& Saúde, v.4. n.1. ed. 22. jan./fev., 2013. 
BERGFELD, W.F. A lifetime of healthy skin: implications for women. International Journal of Fertility and Women's Medicine, v.44, n.2, p.83-95. mar/abr, 1999.

BITENCOURT, S. Tratamento de estrias albas com galvanopuntura: benéfico para a estética, estresse oxidativo e perfil lipídico. 2007. 38 f. Dissertação (Mestrado em Biologia Celular e Molecular). Pontifícia Universidade Católica do Rio Grande do Sul, Porto Alegre, 2007.

BONETTI, V. B. Incidência de estrias em acadêmicos da Faculdade Assis Gurgacz, identificando sua principal causa. Cascavel, 2007. Monografia (Graduação em Fisioterapia). Disponível em: https://pt.scribd.com/document/245108173/Incidenciade-Estrias-Em-Academicos-Da-Faculdade-Assis-Gurgacz-Identificando-a-SuaPrincipal-Causa. Acesso em: 01 abr. 2019.

BORGES, F. S. Dermato-funcional: modalidades terapêuticas nas disfunções estéticas. 2. ed. São Paulo: Phorte, 2010.

BRAGATO, P.E.; FORNAZARI, L.P.; DEON, K.C. Aplicação de eletrolifting em rugas faciais: relato de caso. Revista UNIANDRADE, v.14. n.2, p.131-143, 2013.

BRAIT, D. C. et al. Microagulhamento associado a fatores de crescimento e vitamina C no tratamento de estrias, fibroe dema geloide e flacidez tissular na região glútea. Fisioterapia Brasil, v.19, n.1, p.80-88, 2018.

BRASIL. Saúde da Família: uma estratégia para a reorganização da atenção básica. Brasília-DF, 1997.

BRAVIM, A. R. M., KIMURA, E. M. O uso da eletroacupuntura nas estrias atróficas: uma revisão bibliográfica Brasília, 2007. Disponível em: http://www.portalunisaude.com.br/downloads/eletroacupuntura_nas_estrias.pdf. Acesso em: 01 abr. 2019.

CORDEIRO, R.C.T.; MORAES, A.M. Striae distensae: fisiopatologia. Surgical \& Cosmetic Dermatology, v.1, n.3, p.137-140, 2009. Disponível em: 
<http://www.surgicalcosmetic.org.br/exportar-pdf/1/1_n3_31_pt/Striae-distensae-fisiopatologia> Acessado em: 02 abr. 2019.

COSTA, P.H.V.; SILVA, F.S. Efetividade da corrente galvânica/eletrolifting no tratamento de estrias albas na região glútea. Revista Interdisciplinar Ciências Médicas, Belo Horizonte, Minas Gerais, v2. n.2., p.14-21, 2018

COSTA, R. S. Principais métodos para tratamento estético de estrias. 2016. Monografia (Pós-graduação em Lato Sensu em Biomedicina Estética). INESP e Centro de Capacitação Educacional, Recife - PE.

DAL GOBBO, P. Estética facial essencial: orientações para profissional de estética. São Paulo: Atheneu, 2010.

FACUNDO, D. R. Utilização do eletrolifting e da carboxiterapia para tratamentos de estrias. 2014. Monografia (Graduação em Fisioterapia). Faculdade de Educação e Meio Ambiente, Ariquemes - RO.

FURLANI, L. A. et al. Estrias: fator de risco para distopia urogenital?. Surgical Cosmetic Dermatology, v.2, n.1, p.18-22, 2010. Disponível em: $<$ http://www.surgicalcosmetic.org.br/detalhe-artigo/49/Estrias--fator-de-riscoparadistopia-urogenital>. Acesso em: 01 abr. 2019.

GALDINO, A. P. G.; DIAS, K. M.; CAIXETA, A. Análise comparativa do efeito da corrente microgalvânica: estudo de caso no tratamento de estrias atróficas. Revista Eletrônica "Saúde CESUC", n.1, 2010.

GIL, A. C. Como elaborar projeto de pesquisa. 4 ed. São Paulo: Atlas, 2007.

GUIRRO, E.C.O.; GUIRRO R.R.J. Fisioterapia dermato-funcional: fundamentos, recursos, patologias. 3. ed. rev. e ampl. São Paulo: Manole, 2004. 560 p.

JUNIOR, A. A. S. et al. Estrias: fisiopatologia, principais tratamentos estéticos. [2013?]

Disponivel

em: 
$<$ https://semanaacademica.org.br/system/files/artigos/estrias_fisiopatologia_principai S_tratamentos_esteticos.pdf> Acesso em: 17 abr. 2019.

MAIA, $M$ et al. Estrias de distensão na gravidez: fatores de risco em primíparas. Anais Brasileiros de Dermatologia. Rio de Janeiro, v.84, n.6, p.599-605, 2009.

MAIA, M. Tratado de medicina estética. 2. ed. São Paulo: Roca, 2011.

MATOS, D. M. R.; COSTA, K. L. C. Estrias X recursos fisioterápicos: revisão. Revista Científica Multidisciplinar Núcleo do Conhecimento. a.4, ed.5, v.6, p.05-20, maio 2019.

MCCRUDDEN, M.T. et al. Microneedle applications in improving skin appearance. Experimental Dermatology, abr., 2015. Disponível em: <https://onlinelibrary.wiley.com/doi/full/10.1111/exd.12723> Acesso em: 9 jan. 2019.

MEYER, P.F. et al. Aplicação da galvanoterapia em uma máquina de tatuar para tratamento de estrias. Revista Fisioterapia Brasil, v.9. 2009.

Moreira et al. A Fisioterapia Dermato-funcional no tratamento de estrias: Revisão de literatura. Revista Científica da UNIARARAS, Araras - SP, v. 1, n. 2, 2013. Disponível em: <http://www.uniararas.br/revistacientifica/_documentos/art.3-0082012.pdf >. Acesso em: 09 jan. 2019.

OGLIARI, M. et al. Uso do eletrolifiting para melhorar a aparência da pele. In: Congresso Brasileiro Interdisciplinar na Promoção da Saúde. 2016. Disponível em: https://online.unisc.br/acadnet/anais/index.php/CBIPS/article/view/15917. Acesso em: 02 fev. 2019.

OLIVEIRA, E. L. Efeito da corrente microgalvânica invasiva em estrias albas: estudo histopatológico. Dissertação (Mestrado em Fisioterapia). Universidade Metodista de Piracicaba - Faculdade de Ciência da Saúde. Piracicaba, 2013.

PEDRO, C. F. P.; AUGUSTO, L. C. S.; OLIVEIRA, L. M. Estudo comparativo entre a galvanopuntura e a escarificação no tratamento das estrias atróficas brancas em 
mulheres entre 20 e 25 anos. Universitári@ - Revista Científica do Unisalesiano, Lins - SP, a.6, n.13, jul-dez, 2015.

REBONATO, T.A. et al. Aplicação de microgalvanopuntura em estrias cutâneas albas. Revista Movimento e Saúde, v.4. p.1-6, 2012.

RUSENHACK, C. Terapia por microgalvânica em dermato-funcional. Fisio \& Terapia, Rio de Janeiro. n.8. p.24-26. 2004.

SAMPAIO, S. A. P. Dermatologia de Sampaio e Rivitti, 4. ed. São Paulo: Artes Médicas, 2018.

SANTOS, M.S.; OGATA, G. O uso da galvanopuntura no tratamento das estrias atróficas: uma revisão bibliográfica. 2012. Disponível em: <http://portalbiocursos.com.br/ohs/data/docs/19/66_-

_O_uso_da_galvanopuntura_no_tratamento_das_estrias_atrYficas.pdf $>$. Acesso em: 20 maio 2019.

SILVA, C. L. C. et al. Comparativo entre galvanopuntura e microagulhamento. A prática interdisciplinar alimentado a ciência. In: 18 ${ }^{\text {a }}$ Semana de Pesquisa da Universidade Tiradentes. 24 a 28 out., 2016. Anais... Aracaju, Sergipe: Universidade Tiradentes/Estética e Cosmética, 2016.

SILVA, M. L.; SILVA, V. G.; ROSA, P. V. Análise dos efeitos da utilização do eletrolifting e do microagulhamento no tratamento das estrias atróficas. Revista Biomotriz, Rio Grande do Sul, v.11, n.1, abr., 2017.

SILVA, T.M. et al. Tratamento de estria Alba com o uso de eletrolifting. Revista Terra e Cultura: cadernos de ensino e pesquisa, Centro Universitário Filadélfia. Londrina, PR, v. 33, NESP 67, jun. 2018.

SILVEIRA, C. F. C. Utilização de corrente microgalvânica para o desenvolvimento de dois protocolos para tratamento de estrias albas. 2016. 109 f. Dissertação 
(Mestrado em Engenharia Biomédica). Programa de Pós-Graduação em Engenharia Biomédica, Universidade Tecnológica Federal do Paraná. Curitiba, 2016.

VANZIN, S. B.; CAMARGO, C. P. Entendendo Cosmecêuticos: diagnósticos e tratamentos. São Paulo: Santos, 2011.

VENTURA, D. B. S. O uso da corrente galvânica filtrada nas estrias atróficas. Revista Fisiobrasil: atualização científica, n. 62, nov/dez 2003.

WHITE, P.A.S. et al. A. Efeitos da galvanopuntura no tratamento das estrias atróficas. Revista Brasileira de Fisioterapia, Rio de Janeiro, v.9, n.1, p.53-58, jan/fev. 2008..

Enviado: Junho, 2019.

Aprovado: Julho, 2019. 